\title{
Predictive factors for renal failure and a control and treatment algorithm
}

\author{
Denise de Paula Cerqueira ${ }^{1}$ \\ José Roberto Tavares ${ }^{2}$ \\ Regimar Carla Machado ${ }^{2}$
}

\begin{abstract}
Objectives: to evaluate the renal function of patients in an intensive care unit, to identify the predisposing factors for the development of renal failure, and to develop an algorithm to help in the control of the disease. Method: exploratory, descriptive, prospective study with a quantitative approach. Results: a total of 30 patients (75.0\%) were diagnosed with kidney failure and the main factors associated with this disease were: advanced age, systemic arterial hypertension, diabetes mellitus, lung diseases, and antibiotic use. Of these, 23 patients (76.6\%) showed a reduction in creatinine clearance in the first 24 hours of hospitalization. Conclusion: a decline in renal function was observed in a significant number of subjects, therefore, an algorithm was developed with the aim of helping in the control of renal failure in a practical and functional way. Descriptors: Renal Insuficiency; Intensive Care Units; Oliguria.
\end{abstract}

\footnotetext{
${ }^{1}$ RN, Specialization student in Cardiology Nursing, Universidade do Vale do Paraíba, São José dos Campos, SP, Brazil. 2 PhD, Professor, Universidade do Vale do Paraíba, São José dos Campos, SP, Brazil.
}

Corresponding Author: Denise de Paula Cerqueira Rua Dr. José de Moura Resende, 111 Vila Tesoura

CEP: 12221-470, São José dos Campos, SP, Brasil E-mail: denise_cerq@hotmail.com
Copyright $\odot 2014$ Revista Latino-Americana de Enfermagem This is an Open Access article distributed under the terms of the Creative Commons Attribution Non-Commercial License (CC BY-NC).

This license lets others distribute, remix, tweak, and build upon your work non-commercially, and although their new works must also acknowledge you and be non-commercial, they don't have to license their derivative works on the same terms. 


\section{Introduction}

Renal failure (RF) is a clinical syndrome characterized by a decrease in renal function with accumulation of metabolites and electrolytes in the body. Renal failure can be subdivided into acute renal failure (ARF) and chronic renal failure (CRF) according to the length of development of the disease ${ }^{(1-3)}$. Acute renal failure is defined as the abrupt loss of the glomerular filtration of the kidneys with a subsequent alteration in the hydroelectrolyte and acid-base balance in the body ${ }^{(4-5)}$. This imbalance, in turn, leads to the accumulation of substances in the blood such as urea and creatinine ${ }^{(3)}$. Recognition of RF in the initial stages is critical to delay the evolution of the disease, making renal recovery possible and preventing the individual from needing to undergo renal replacement therapy ${ }^{(2-3)}$. Some individuals, in particular, should be monitored carefully in relation to glomerular filtration. Groups that are classified as at risk for the development of RF include diabetic or hypertensive patients, those with cardiovascular disease or a family history of renal failure, patients with other renal diseases, and those of black race ${ }^{(3-4)}$.

It is noteworthy that patients affected by ARF, in its early stages, may or may not present a decrease in the urine volume. However, oliguria is one of the indications that the glomerular filtration of the kidneys is beginning to fail(3,5). In 2002, the Acute Dialysis Quality Initiative (ADQI) developed the RIFLE system that classifies ARF according to the degree of injury (Risk - class R; Injury - class I; Failure - Class F; Loss - Class L; and End Stage - Class E) ${ }^{(4-6)}$. The RIFLE score considers the glomerular filtration rate from the creatinine clearance $(\mathrm{CrCl})$, which can be obtained using equations such as the Cockcroft-Gault formula - (140 - age in years) $\times$ body weight / $72 \times$ serum creatinine, applied to both sexes, with the result multiplied by the constant $0.85^{(2,7-8)}$.

In Brazil there are few epidemiological studies on ARF. However, through research conducted in many Brazilian hospitals, it was found that an increasing number of patients are developing this disease during the hospitalization period. It was also observed that it affects mainly critically ill patients and those with comorbidities, making them susceptible to acute renal disease $e^{(4,9-10)}$. Studies conducted in intensive care units (ICU) have demonstrated the high mortality of patients with ARF and that many of them developed the disease after a period of hospitalization in these units $^{(5,10-11)}$. Given this context, it can be seen that the nurse has an important role in the prevention of RF, by actively participating in the care plan. The importance should be highlighted of conducting precise and swift nursing actions, based on evidence, in order to provide appropriate care. Therefore, when considering the importance of optimizing the work of the nurse through tools that assist the care, it becomes necessary to develop instruments to guide and support the decisions of the nurse in determining the appropriate care for the RF patient in the ICU.

The aims of this study were to evaluate the renal function of patients hospitalized in the ICU, to identify predisposing factors for the development of RF, and to develop an algorithm to help in the control of the disease.

\section{Method}

This exploratory, descriptive, prospective study used a quantitative approach. To extract the information a data collection instrument was prepared, based on the scientific literature ${ }^{(2-6,8-13)}$. In order to refine the instrument regarding the coverage, clarity and relevance, a review was performed by four nurses and one physician, who possessed the title of intensive care specialist or had a minimum of two years experience in this area, which was the criteria for the selection of the experts. The data collection instrument was divided into Part A and Part B, with the first composed of the characterization of the subject, including sociodemographic data, personal history and habits of the patient. The second part consisted of the clinical data, which considered information on the diagnosis at admission, clinical progression, treatment, laboratory examinations, hydric balance, and the fate of the patient (termination of the participation of the patient in the study). The research protocol was submitted to the Research Ethics Committee of the University of Taubaté and was approved under protocol No. 563/11.

The study was conducted in a general ICU of a hospital in the Vale do Paraíba from January to June 2012. The sample consisted of 40 patients hospitalized in the ICU who did or did not present renal failure. The inclusion criteria established were, to be patients 18 years of age or over, of either gender, with urinary catheterization for greater accuracy in the measurement of the urine volume, with $1.4 \mathrm{mg} / \mathrm{dL}$ or less of serum creatinine, and at least 24 hours of hospitalization. Subjects with chronic renal failure that were undergoing dialysis were excluded. 
Data were collected from the patient records since their hospitalization in the ICU, respecting the standard established to collect data, such as time and period of sampling, and manner of collection. It should be noted that the collection was conducted only by the researchers. The data collection was terminated from the time when the bladder catheter was removed, as it was no longer possible to measure the urine volume; after the discharge from the ICU; or with the death of the patient. Accordingly, this defined the period of duration of the patients in the study. Daily monitoring of renal function was conducted in these patients by calculating creatinine clearance $(\mathrm{CrCl})$ through the CockcroftGault formula and the urine volume. Subsequently, the patients who developed RF, the triggering factors, and the development stage of the disease were identified, with the use of the RIFLE scale.

Initially, all the variables were analyzed descriptively. The quantitative variables were described through the means and standard deviation; and the qualitative variables were presented as absolute (amount observed) and relative (percentage) frequencies. For the analysis, the patients were divided into two groups according to the classification: with renal failure and without renal alteration, with a descriptive analysis performed and the descriptive level of the appropriate tests presented. To test the association between the categorical variables and the groups, Fisher's exact test was used, while the Mann-Whitney test was used to compare the two groups regarding the continuous variables. The KolmogorovSmirnov test was also used to test the normality of the variables (whether they were significant or not). The level of significance for the tests was $5 \%(\alpha=0.05)^{(14)}$.

\section{Results}

The results, in general, had no relevant statistical significance due to the fact that the sample was composed of a small number of subjects $(n=40)$, however, from the clinical perspective it was possible to note the differences between the groups analyzed.

Table 1 shows that RF was present in 30 patients (75.0\%). The groups differed only in terms of age (RF: 65.87 [SD = 14.4] years; Without Renal Alteration: 51.0 $[S D=14.2]$ years; $p=0.007)$ and diagnosis at admission (Neurological Surgery: RF: 3.3\%; Without Renal Alteration: $30.0 \%, p=0.042)$. However, for the other variables evaluated there were no statistical differences.

Table 1 - Distribution of the patients with Renal Failure acquired during the hospitalization in the ICU and those without renal alteration. São José dos Campos, SP, Brazil 2012

\begin{tabular}{|c|c|c|c|c|c|}
\hline \multirow{2}{*}{ Sociodemographic Data } & \multicolumn{2}{|c|}{ Renal Failure (N=30) } & \multicolumn{2}{|c|}{ Without Renal Alteration $(\mathrm{N}=10)$} & \multirow{2}{*}{ P-value } \\
\hline & $\mathbf{n}$ & $\%$ & $\mathbf{n}$ & $\%$ & \\
\hline Age (years) & \multicolumn{2}{|c|}{$65.87(\mathrm{SD}=14.4)$} & \multicolumn{2}{|c|}{$51.0(\mathrm{SD}=14.2)$} & 0.007 \\
\hline Male & 18 & 60.0 & 5 & 50.0 & 0.717 \\
\hline Weight (Kg) & \multicolumn{2}{|c|}{$70.7(S D=17.5)$} & \multicolumn{2}{|c|}{$79.0(\mathrm{SD}=15.5)$} & 0.258 \\
\hline \multicolumn{6}{|l|}{ Underlying Diseases } \\
\hline Systemic Arterial Hypertension & 18 & 60.0 & 3 & 30.0 & 0.148 \\
\hline Diabetes Mellitus & 9 & 30.0 & 1 & 10.0 & 0.401 \\
\hline Chronic Obstructive Pulmonary Disease & 5 & 16.7 & 2 & 20.0 & 1.000 \\
\hline Cardiopathy & 4 & 13.3 & 0 & 0 & 0.556 \\
\hline Hepatopathy & 1 & 3.3 & 1 & 10.0 & 0.442 \\
\hline Others & 9 & 30.0 & 3 & 30.0 & 1.000 \\
\hline \multicolumn{6}{|l|}{ Admission diagnosis } \\
\hline Orthopedic Surgery & 3 & 10.0 & 1 & 10.0 & 1.000 \\
\hline Cardiac Surgery & 2 & 6.7 & 1 & 10.0 & 1.000 \\
\hline Neurological Surgery & 1 & 3.3 & 3 & 30.0 & 0.042 \\
\hline Liver transplantation & 2 & 6.7 & 1 & 10.0 & 1.000 \\
\hline Cerebrovascular Disease & 5 & 16.7 & 2 & 20.0 & 1.000 \\
\hline Acute Myocardial Infarction & 1 & $3.3 \%$ & 0 & 0 & 1.000 \\
\hline Acute Respiratory Failure & 6 & 20.0 & 2 & 20.0 & 1.000 \\
\hline Pneumonia & 8 & 26.7 & 0 & 0 & 0.165 \\
\hline Sepsis & 1 & 3.3 & 0 & 0 & 1.000 \\
\hline \multicolumn{6}{|l|}{ Medication } \\
\hline Non Steroid anti-inflammatories & 8 & 26.7 & 0 & 0 & 0.165 \\
\hline Diuretics & 15 & 50.0 & 4 & 40.0 & $\begin{array}{c}0.721 \\
\text { (continu }\end{array}$ \\
\hline
\end{tabular}


Table 1 - (continuation)

\begin{tabular}{|c|c|c|c|c|c|}
\hline \multirow{2}{*}{ Sociodemographic Data } & \multicolumn{2}{|c|}{ Renal Failure $(\mathrm{N}=30)$} & \multicolumn{2}{|c|}{ Without Renal Alteration $(\mathrm{N}=10)$} & \multirow{2}{*}{ P-value } \\
\hline & $\mathbf{n}$ & $\%$ & $\mathbf{n}$ & $\%$ & \\
\hline Antihypertensives $\mathrm{ACEl}^{*}$ & 10 & 33.3 & 5 & 50.0 & 0.457 \\
\hline Antibiotics & 26 & 86.7 & 10 & 100.0 & 0.556 \\
\hline Immunosuppressives & 1 & 3.3 & 1 & 10.0 & 0.442 \\
\hline Vasoactive drugs & 7 & 23.3 & 1 & 10.0 & 0.653 \\
\hline Outcomes & & & & & 0.062 \\
\hline Discharge & 19 & 63.3 & 5 & 50.0 & \\
\hline Death & 9 & 30.0 & 1 & 10.0 & \\
\hline Bladder Probe Withdrawal & 2 & 6.7 & 2 & 20.0 & \\
\hline Reversal & 0 & 0 & 1 & 10.0 & \\
\hline Transfer & 0 & 0 & 1 & 10.0 & \\
\hline
\end{tabular}

*ACEI=angiotensin converting enzyme inhibitors

The age groups (years) were statistically similar in both groups. It was also observed that $70 \%$ of the patients with RF were 60 years of age or more.

Table 2 shows the moment when the subjects presented alterations in creatinine clearance $(\mathrm{CrCl})$. Note that $76.6 \%$ presented $\mathrm{CrCl}$ below $90 \mathrm{~mL} / \mathrm{min} / 1.73 \mathrm{~m}^{2}$ within the first 24 hours of hospitalization.

Table 2 - Descriptive measures of $\mathrm{CrCl}$ less than or equal to $90 \mathrm{~mL} / \mathrm{min} / 1.73 \mathrm{~m}^{2}$. São José dos Campos, SP, Brazil $2012(\mathrm{~N}=30)$

\begin{tabular}{lcccc}
\hline \multicolumn{1}{c}{ CrCl Time } & $\mathbf{n}$ & $\%$ & Mean & $\begin{array}{c}\text { Standard } \\
\text { Deviation }\end{array}$ \\
\hline $24 \mathrm{~h}$ & 23 & 76.6 & 56.47 & 16.78 \\
$48 \mathrm{~h}$ & 4 & 13.3 & 67.93 & 19.79 \\
After 96h & 3 & 10.0 & 78.53 & 7.10
\end{tabular}

$\mathrm{CrCl}$ Time $=$ Creatinine Clearance Time

Conversely, in Table 3, the onset of alterations in serum creatinine (greater than or equal to $1.4 \mathrm{mg}$ / $\mathrm{dL}$ ) occurred in the subjects within the first 48 hours, i.e., 24 hours after the onset of the alteration in $\mathrm{CrCl}$.

The analysis of the stages of evolution of RF in the patients, according to the RIFLE scale, can be seen in Table 4, highlighting stages II (46.6\%) and III $(53.3 \%)$.
Table 3 - Descriptive Measures of Creatinine greater than or equal to $1.4 \mathrm{mg} / \mathrm{dL}$. São José dos Campos, SP, Brazil $2012(\mathrm{~N}=12)$

\begin{tabular}{lcccc}
\hline \multicolumn{1}{c}{ SCr Time } & $\mathbf{n}$ & $\%$ & Mean & $\begin{array}{c}\text { Standard } \\
\text { Deviation }\end{array}$ \\
\hline $24 \mathrm{~h}$ & 2 & 16.6 & 1.56 & 0.18 \\
$48 \mathrm{~h}$ & 5 & 41.6 & 1.65 & 0.10 \\
$72 \mathrm{~h}$ & 2 & 16.6 & 1.81 & 0.49 \\
After 96h & 3 & 25.0 & 1.56 & 0.20 \\
\hline
\end{tabular}

$\mathrm{SCr}$ Time=serum creatinine time - moment at which there was an alteration in the serum creatinine

Table 4 - Stages of evolution of Renal Failure, according to the RIFLE scale. Only the subjects who developed Renal Failure. São José dos Campos, SP, Brazil 2012 $(\mathrm{N}=30)$

\begin{tabular}{lcc}
\hline \multicolumn{1}{c}{ Renal Failure Stages } & n & $\%$ \\
\hline I or class R & 00 & 0 \\
II or class I & 14 & 46.6 \\
III or class F & 16 & 53.3 \\
IV or class L & 00 & 0 \\
V or class E & 00 & 0 \\
\hline
\end{tabular}

From the survey data and with the help of the scientific literature, an algorithm (Figure 1) was elaborated as a manual with guidelines to assist in the prevention, identification, and control of renal failure, and thus the systematization of the care.

\begin{tabular}{|l|l|}
\hline \multicolumn{1}{|c|}{ Action } & \multicolumn{1}{c|}{ Clinical history } \\
\hline \multicolumn{1}{|c|}{ Renal Failure Algorithm } \\
\hline Identify possible causes & loss of extracellular fluid (hemorrhage, diarrhea, vomiting); \\
\hline Identify risk factors & $\begin{array}{l}\text { elderly (>60 years), arterial hypertension, diabetes mellitus, cardiopathy, lung disease, } \\
\text { kidney disease, recent surgeries. }\end{array}$ \\
\hline Calculation of the $\mathrm{CrCl}$ & Cockcroft \& Gault formula \\
\hline
\end{tabular}

(The Figure 1 continue in the next page...) 


\begin{tabular}{|c|c|}
\hline \multicolumn{2}{|r|}{ Renal Failure Algorithm } \\
\hline \multicolumn{2}{|r|}{ Physical examination } \\
\hline Action & Description \\
\hline Observe oliguria (volume of urine $<400 \mathrm{~mL}$ in 24 hours) & hypovolemia, arterial hypotension, urinary tract obstruction, urinary retention. \\
\hline Signs and Symptoms & $\begin{array}{l}\text { back or suprapubic pain; fever; skin rash; difficulty in urinating; mental confusion, agitation } \\
\text { or low level of consciousness (uremia) }\end{array}$ \\
\hline \multicolumn{2}{|r|}{ Laboratory diagnosis } \\
\hline Action & Description \\
\hline Blood & urea, creatinine, sodium bicarbonate, sodium, potassium, uric acid; \\
\hline Urine & urinary sediment, sodium, creatinine, and osmolality. \\
\hline \multicolumn{2}{|r|}{ Prevention } \\
\hline Action & Description \\
\hline Establish renal function baseline & through the measurement of blood serum creatinine and the $\mathrm{CrCl}$ calculation; \\
\hline Optimize the clinical conditions & $\begin{array}{l}\text { adequate intravascular volume, maintain blood pressure (mean arterial pressure }>80 \mathrm{mmHg} \text { ), } \\
\text { hematocrit above } 30 \% \text {; glucose less than } 100 \mathrm{mg} / \mathrm{dL} \text {; adequate tissue oxygenation; }\end{array}$ \\
\hline Adjust medication doses according to renal function & Tozer equation - NEFROCALC \\
\hline Maintain adequate hydration and monitor renal function & Hydric balance \\
\hline
\end{tabular}

Source: NEFROCALC 1.0. Available at: http://www.sbn.org.br/equacoes/link/nefrocalc.htm

Figure 1 - Renal failure algorithm

\section{Discussion}

Renal failure is responsible for the high rate of hospital mortality, especially in intensive care units (ICU). From this information, this study sought to monitor the renal function of patients admitted to an ICU to identify those who developed renal failure, the stages of evolution, and the factors that may have triggered the disease. The study sample was composed of a small number of patients (40), due to the high rate of hospitalization of patients with CRF with creatinine greater than $1.4 \mathrm{mg} / \mathrm{dL}$, the high turnover of patients, i.e., patients recovering post-surgery that remained in the ICU for less than 24 hours, and those who had incomplete medical records.

In the data analysis, the subjects were analyzed regarding the presence of $\mathrm{RF}$ when they presented $\mathrm{CrCl}<90 \mathrm{~mL} / \mathrm{min} / 1.73 \mathrm{~m}^{2}$ during the hospitalization in the ICU and those who already had $\mathrm{CrCl}<90 \mathrm{~mL} /$ $\min / 1.73 \mathrm{~m}^{2}$ at the time of admission. However, the subjects without RF who did not present renal alterations were characterized as having a $\mathrm{CrCl}>90 \mathrm{~mL} /$ $\min / 1.73 \mathrm{~m}^{2}$. Next, a comparative analysis between the RF and without renal alteration groups was performed. According to the literature, the individual with $\mathrm{CrCl}$ lower than $90 \mathrm{~mL} / \mathrm{min} / 1.73 \mathrm{~m}^{2}$ is in the early stage of loss of kidney function. At this stage, the levels of urea and plasma creatinine are still normal and there are no significant clinical signs or symptoms of renal failure ${ }^{(7,15)}$.

In the sociodemographic analysis of this study, it was noted that the group over 60 years of age had a higher incidence of renal failure. This can be explained by the fact that with advancing age, the glomerular filtration rate decreases as part of the body aging process ${ }^{(9,16-17)}$. The analysis of the associations between comorbidities and acute renal failure in the literature is scarce. Studies show the association of a particular co-morbidity that may or may not influence the onset of ARF in critically ill patients(18-19). In this study, there were high percentages of comorbidities present in the RF patients. The comorbidities described in the scientific literature, such as diabetes mellitus, arterial hypertension, cardiopathy, and vascular disorders, are factors that predispose individuals to develop $\mathrm{RF}^{(10)}$.

The underlying diseases more frequently presented in this study were systemic arterial hypertension $(\mathrm{SAH})$, diabetes mellitus (DM), chronic obstructive pulmonary disease (COPD), and cardiopathy. In many studies these diseases are also highlighted as a risk factors for the development of $\mathrm{RF}^{(9-10,19-21)}$. However, during hospitalization, complications presented by patients such as sepsis, septic and hypovolemic shock, hypotension, and pulmonary and metabolic diseases, may be associated with renal dysfunction ${ }^{(10,17)}$. One study found that sepsis was the main triggering factor for ARF among patients during hospitalization in the ICU(19). The admission diagnosis variable generally included clinical factors, such as pneumonia (pneumonia), acute respiratory failure (ARP) and cerebrovascular disease (CVD), as well as orthopedic and neurological surgeries. It is noted in the scientific literature that these factors 
predispose patients to the development of $\mathrm{RF}^{(9-10,19)}$. The medications used in the treatment of the diseases with higher prevalence in this study were antibiotics, diuretics and antihypertensives and ACEI inhibitors. According to the literature, these drugs can enhance renal alterations in patients with RF, or may even lead to the development of the disease ${ }^{(3,12)}$.

By analyzing the RF, it was found that $75 \%$ of the patients developed this disease. According to the development stage of the RF (from the RIFLE scale), $47 \%$ of the patients had class I of the disease and $53 \%$ (16) class F. These findings corroborate another study which showed that, when analyzing the renal function of patients in an ICU, who presented ARF, classes R, I and $F$ of the RIFLE scale were more prevalent ${ }^{(5)}$. In Table 3 , the onset of changes in serum creatinine (greater than or equal to $1.4 \mathrm{mg} / \mathrm{dL}$ ) occurred in the subjects within the first 48 hours, i.e., 24 hours after the onset of the change in $\mathrm{CrCl}$. However, the scientific literature emphasizes that creatinine can not be used as a parameter for the detection of changes in the glomerular filtration rate, since, when this is elevated the kidney is already suffering ${ }^{(7-8)}$.

A mortality rate of $25 \%$ was observed, of which $30 \%$ corresponded to subjects who presented RF. The mortality of patients with RF is highly variable, with it depending on the development stage of the disease, the clinical treatment, aggravating health factors, the physical condition of the patient, and other factors that are not directly related to kidney disease ${ }^{(10,22)}$. However, the mortality of these patients still remains at high levels, which reinforces the need for effective and careful prevention of $\mathrm{RF}^{(10,23)}$. Recent study analyzed 564 patients with and without ARF in an ICU, comparing the clinical features and development, as well as the identification of risk factors associated with the development of ARF and with the mortality, showing that $25 \%$ of the patients developed ARF during the hospitalization period and that the mortality was $62 \%{ }^{(22)}$.

Studies on the role of nursing in the prevention of nosocomial renal disease are scarce. However, this fact does not make the issue less important, because nurses, through resources that guide them in the prevention and progression of $\mathrm{RF}$, will be able to perform their actions in a safer and more effective manner. Therefore, the development of an action plan to identify signs of renal alterations qualifies and systematizes the care.

\section{Conclusions}

It was observed that the majority of the patients presented $\mathrm{RF}$, highlighted by the change in serum creatinine ( $\mathrm{SCr}$ ) after 48 hours of ICU admission and by alterations in creatinine clearance $(\mathrm{CrCl})$ in the first 24 hours. This shows that $\mathrm{SCr}$ is not a reliable parameter for the early diagnosis of IR. The main factors associated with the development of RF were advanced age, hypertension, diabetes mellitus, cardiopathy, lung disease, and prolonged use of antibiotics. The daily evaluation of renal function in critically ill patients can minimize renal injury during hospitalization. Therefore, an algorithm was developed in order to serve as a guide to assist in the prevention and control of RF. The algorithm was developed considering the practicality of its use, thus serving as a quick tool to support healthcare professionals in hospital inpatient units.

\section{References}

1. Stevens LA, Levey AS. Measurement of kidney function. Med Clin North Am. 2005;89: 457-73.

2. Sociedade Brasileira de Nefrologia. Diretrizes de insuficiência renal aguda [Internet]. 2007. [acesso 28 julho 2011]; Disponível em: http://www.jbn.org.br/ diretrizes.asp

3. Silva VTC, Yu L. Consulta nefrológica em 10 minutos: abordagem clínica da oligúria. Serviço de Nefrologia do Hospital das Clínicas da USP. J Bras Nefrol. 2009;31(3):173-4.

4. Santos ER. Associação do RIFLE com letalidade e tempo de internação em pacientes críticos com lesão renal aguda. Rev Bras Ter Intensiva. 2009; 21(4):359-68.

5. Young WP, Eun Ah $\mathrm{H}$, Jang $M H$, Park SB, Chul-hyun K. The Risk Factors and Outcome of Acute Kidney Injury in the Intensive Care Units. Korean J Intern Med. 2010;25(2):181-7.

6. Mehta RL, Pascual MT,Gruta CG, Zhuang S, Chertow GM. Refining predictive models in critically ill patients with acute renal failure. J Am Soc Nephrol. 2002; 13(5):1350-7.

7. Sodré FL, Costa JCB, Lima JCC. Avaliação da função e da lesão renal: um desafio laboratorial. J Bras Patol Med Lab. 2007;43(5):329-37.

8. Pecoits-Filho R. Diagnóstico de doença renal crônica: avaliação da função renal. J Bras Nefrol. 2004; 26(3 supl 1):4-5.

9. Bernardina LD, Diccini S, Belasco AGS, Bittencourt ARC, Barbosa DA. A evolução clínica de pacientes com 
insuficiência renal em unidade de terapia intensiva. Acta Paul Enferm. 2008;21:174-8.

10. Garcia TPR, Romero MP, Poletti NAA, Cesarino $C B$, Ribeiro RCHM. Principais motivos de internação do paciente com insuficiência renal aguda na unidade de terapia intensiva. Arq Ciênc Saúde. 2005; 12(3):146-50.

11. Carmo PAV, Amaral CF, Paiva ARB, Ribeiro CCOS, Ramalho GT, Bastos MG, et al. Insuficiência renal aguda dialítica: experiência em hospital universitário. J Bras Nefrol. 2006; 28(1):7-14.

12. Pinto PS, Carminatti M, Lacet $T$, Rodrigues DF, Nogueira LO, Bastos MG, et al. Insuficiência renal aguda nefrotóxica: prevalência, evolução clínica e desfecho. J Bras Nefrol. 2009;31(3):183-9.

13. Vukusich AC, Alvear FM, Villanueva PA, González $\mathrm{CT}$, Olivari FP, Alvarado NA, et al. Epidemiología de la insuficiencia renal aguda grave: un estudio prospectivo multicéntrico en la Región Metropolitana. Rev Méd Chile. 2004;132(11):1355-61.

14. Bussab WO, Morettin P. Estatística básica. $6^{a}$ ed. São Paulo: Saraiva; 2010.

15. Koyner JL, Vaidya VS, Bennett MR, Worcester E, Akhter SA, Raman J, et al. Urinary biomarkers in the clinical prognosis and early detection of acute kidney injury. Section of Nephrology, Department of Medicine, University of Chicago, Chicago, Illinois, USA. Clin J Am Soc Nephrol. 2010;5(12):2154-65.

16. Romão JE Júnior, Haiashi ARM, Vidonho AF Júnior, Abensur H, Quintaes PSL, Araújo MRT, et al. Causas e prognóstico da insuficiência renal aguda hospitalar em pacientes idosos. Rev Assoc Med Bras. 2000; 46(3):212-7.

17. Kusumota L, Rodrigues RAP, Marques $S$. Elderly persons with chronic kidney failure: health status alterations. Rev. Latino-Am. Enfermagem. 2004;12(3):525-32.

18. Murugan R, Karajala-Subramanyam V, Lee M, Yende $S$, Kong $L$, Carter $M$, et al. Acute kidney injury in nonsevere pneumonia is associated with an increased immune response and lower survival. Kidney Int. 2010;77(6):527-35.

19. Medve L, Antek C, Paloczi B, Kocsi S, Gartner B. Epidemiology of acute kidney injury in Hungarian intensive care units: a multicenter, prospective, observational study. BMC Nephrol. 2011; 12:43.

20. Bezerra KV, Santos JLF. Daily life of patients with chronic renal failure receiving hemodialysis treatment. Rev. Latino-Am. Enfermagem. 2008; 16(4):686-91.
21. Ponce D, Zorzenon CPF, Santos NY, Teixeira UA, Balbi AL. Injúria renal aguda em unidade de terapia intensiva: estudo prospectivo sobre a incidência, fatores de risco e mortalidade. Rev Bras Ter Intensiva. 2011; 23(3):321-6.

22. Chertow GM, Burdick E, Honour M, Bonventre JV, Bates DW. Acute Kidney Injury, Mortality, Length of Stay, and Costs in Hospitalized Patients. J Am Soc Nephrol. 2005; 16: 3365-70.

23. Camerini FG, Cruz I. Cuidados de enfermagem na prevenção da insuficiência renal provocada por contraste após cateterismo. Acta Paul Enferm. 2008; 21(4):660-6.
Received: Nov. 30th 2012 Accepted: Dec. $19^{\text {th }} 2013$ 